\title{
VICI SYNDROME WITH SENSORINEURAL HEARING LOSS AND LARYNGOMALACIA
}

Researchers at Baskent University, Adana, and other centers in Turkey report a 3month-old Turkish girl with Vici syndrome complicated by stridor and laryngomalacia. They also review the clinical features of 15 Vici syndrome patients published in the literature. The Turkish girl was the second child of consanguineous parents, she was admitted with bronchopneumonia, stridor, and failure to thrive, and examination revealed microcephaly, hypopigmentation of the skin, silvery hair, high-arched palate and micrognathia. Neurologic abnormalities included hypotonia, areflexia, cataracts, ocular albinism, and cranial MRI revealed agenesis of the corpus callosum, delayed myelination of cerebral white matter, and hypoplasia of the cerebellar hemisphere and brain stem. EEG showed paroxysmal, bifrontal discharges during sleep. Chest X-ray showed cardiomegaly, echocardiography demonstrated hypertrophic cardiomyopathy, and audiology exam revealed deafness in the left ear. The patient died of a recurrence of bronchopneumonia at 6 months of age.

Of the total 15 patients with Vici syndrome, 6 were girls and 9 boys, and 8 were siblings. Common manifestations include agenesis of the corpus callosum $(100 \%)$, hypotonia (100\%), developmental delay $(100 \%)$, cerebellar and cortical defects $(60 \%)$, cataracts $(60 \%)$, seizures $(60 \%)$, cardiomyopathy, hypopigmentation (albinism), recurrent infections, immunological abnormalities, and sensorineural hearing loss (20\%). Vici syndrome should be considered in the differential diagnosis of an infant with agenesis of the corpus callosum. (Ozkale M, Erol I, Gumus A, Ozkale Y, Alehan F. Vici syndrome associated with sensorineural hearing loss and laryngomalacia. Pediatr Neurol 2012 Nov;47(5):375-8). (Respond: Dr Erol, Division of Neurology, Department of Pediatrics, Adana Teaching and Medical Research Center, Faculty of Medicine, Baskent University, Baraj Yolu 1 Durak, Seyhan 01120, Adana, Turkey. E-mail: ilknur_erol@yahoo.com).

COMMENT. Vici syndrome is a rare phenotypically heterogeneous, autosomal recessive disorder of unknown cause. Also called immunodeficiency with cleft lip/palate, cataract, hypopigmentation and absent corpus callosum. The diagnosis is based on a cluster of clinical symptoms and MRI evidence of structural cerebral defects, typically agenesis of the corpus callosum. The prognosis is poor because of immunological abnormalities and recurrent severe infections. (Vici CD, Sabetta G, Gambarara M, et al. Agenesis of the corpus callosum, combined immunodeficiency, bilateral cataract, and hypopigmentation in two brothers. Am J Med Genet 1988 Jan;29(1):1-8).

\section{GROWTH FAILURE AND OUTCOME IN RETT SYNDROME}

Researchers at the Miami Children's Hospital and other centers in the US studied growth patterns among children with Rett syndrome compared to unaffected children. Growth charts for classic and atypical Rett were created from 9,749 observations of 816 female subjects. Mean growth in classic Rett decreased below that for the normative population at 1 month for head circumference, 6 months for weight, and 17 months for length. Mean BMI was unchanged. Pubertal increases in height and weight were absent in classic Rett patients. Classic Rett was associated with more growth failure than 